\title{
Management of Primary AVN with Total Hip Replacement
}

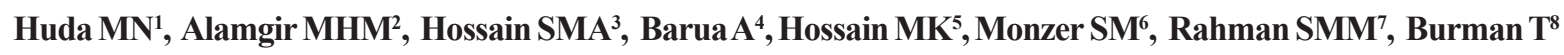

Conflict of Interest: None

Received: 23.08 .2020

Accepted: 27.10 .2020

www.banglajol.info/index.php/JSSMC

Keywords:

Avascular necrosis (AVN), Total Hip Replacement (THR)

\begin{abstract}
Introduction: Avascular necrosis (AVN) of femoral head is a dreadful and disabling condition. Total Hip Replacement (THR) is an effective solution. In this study we have analyzed the results of total hip replacement performed in ShSMCH, Dhaka for AVN offemoral head from July 2018 up to June 2020.
\end{abstract}

Patients and Methods: In this prospective study, 19 total hip replacement were done. All patients were diagnosed as primary AVN of Ficat and Arlet Grade III and IV. Out of 19 patients, 15 patients operated with cementless pressfit implants and 4 patients with cemented implants.

Results: Among the 19 patients 12 were male (63.15\%) and 7 were female (36.85\%). Mean age was 35.57 year. Operation done on right hip in 10 patients (52.63\%) and on left hip 9 patients (47.37\%). All the patients were evaluated pre-operatively and Harris Hip Score was poor ie, average 41.84. Three months post operatively Harris Hip Score improved significantly $47.36 \%$ patients value was $90-100$ ie, excellent, $31.57 \%$ patients value was $80-90$ ie, good and $21.05 \%$ patients value was 70-80 ie, fair. None documented as poor. In complication, 1 patient $(5.26 \%)$ developed serous discharge which resolved with antibiotic treatment after culture and sensitivity.

Conclusion: THR is the most effective method of removing pains and distress of end stage AVN of hip.

[J Shaheed Suhrawardy Med Coll 2020; 12(2): 87-89] DOI: https://doi.org/10.3329/jssmc.v12i2.56888

\section{Introduction}

Avascular necrosis of femoral head is caused by deficient blood supply to the femoral head. It leads to death of bone cells and progressive collapse of femoral head. In advanced stage destruction of acetabulum is also initiated and disables the person. Its main cause is idiopathic. Other causes are corticosteroid medication, trauma, chronic alcololism etc. Total hip replacement is indicated in

1. Dr. Md. Nazmul Huda, Assistant Professor, Department of Orthopedic Surgery, Shaheed Suhrawardy Medical College, Dhaka.

2. Dr. M.H.M Alamgir, Associate Professor, Department of Orthopedic Surgery, Shaheed Suhrawardy Medical College, Dhaka.

3. Dr. S.M Amir Hossain, Associate Professor, Department of Orthopedic Surgery, Shaheed Suhrawardy Medical College, Dhaka.

4. Dr. Anupam Barua, Assistant Professor, Department of Orthopedic Surgery, Shaheed Suhrawardy Medical College, Dhaka.

5. Dr. Mohammad Kamal Hossain, Assistant Professor, Department of Orthopedic Surgery, Chandpur Medical College, Chandpur.

6. Dr. Salahuddin Md. Monzer, Medical Officer, Department of Orthopedic Surgery, Shaheed Suhrawardy Medical College, Dhaka.

7. Dr. S.M Mosheeur Rahman, Junior Consultant (Orthopedic Surgery), Shaheed Suhrawardy Medical College, Dhaka.

8. Dr. Tanusree Burman, Registrar, Department of Orthopedic Surgery, Shaheed Suhrawardy Medical College, Dhaka.

Correspondence to: Dr. Md. Nazmul Huda, Assistant Professor, Department of Orthopedic Surgery, Shaheed Suhrawardy Medical College, Dhaka. Phone No: 01712256002, E-mail: nazmulk50 dmc.nh@gmail.com advanced stage of AVN of femoral head which have not been responded to conservative medications and conservative surgeries like decompression, fibular graft etc. Since its inception in 1950's overall procedure and technology have been improved enormously. Total hip replacement in one of the most successful operation in orthopedic surgery. ${ }^{1}$ It is estimated that more than 950,000 THR were performed globally in $2010 .^{2}$

\section{Patents and Methods}

In this course of prospective study 19 patents with were operated. All patients were diagnosed as primary AVN of femoral head. Age related and post traumatic osteoarthritic cases were excluded from the study. All patients were of Ficat and Arlet grade III and IV stages of AVN. Total hip replacement was performed in lateral decubitous position with lateral approach in our Department of orthopaedic surgery Shaheed Suhrawardy Medical College Hospital, Dhaka. All patients were operated under spinal anaesthesia. Out of 19 patients 15 patients were operated with cementless pressfit implants and 4 patients with cemented implants randomly.

\section{Results}

In this study total number of patient was $19 ; 12$ were male (63.15\% and 7 were female $(36.85 \%)$. 
Table I

\begin{tabular}{lcc} 
& \multicolumn{2}{c}{ Sex Distribution } \\
Sex & Number of Patients & Percentage \\
\hline Male & 12 & $63.75 \%$ \\
Female & 7 & $36.85 \%$ \\
\hline
\end{tabular}

Out of 19 patients operation done on right hip in 10 patients $(52.63 \%)$ and on left hip in 9 patients $(47.37 \%)$.

Table-II

\section{Side of Operation}

\begin{tabular}{lcc} 
Side & Number of Patients & Percentage \\
\hline Right & 10 & $52.63 \%$ \\
Left & 9 & $47.37 \%$ \\
\hline
\end{tabular}

Age range was from 21 years to 57 years. Average age of patients was 35.57 years.

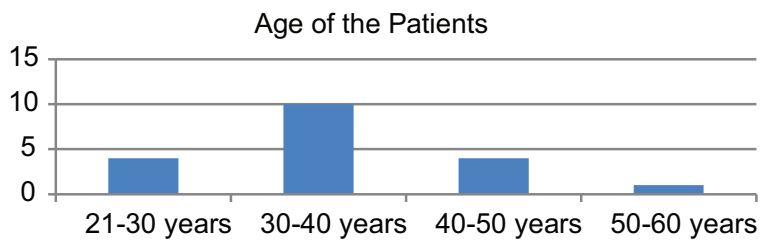

Fig.-1: Age Distribution of the Patients

According to Harris Hip Score value $<70=$ poor, $70-80=$ Fair, 80-90 = Good and 90-100 = Excellent. All patients were evaluated pre-operatively and Harris Hip Score was found poor and average value was 41.84. Three months after THR average Harris Hip Score was 84.42. 9 patients $(47.36 \%)$ point $>90$ i,e, excellent, 6 patients points between $80-90$ i,e, good \& 4 patients points between 70-80 i,e, fair.

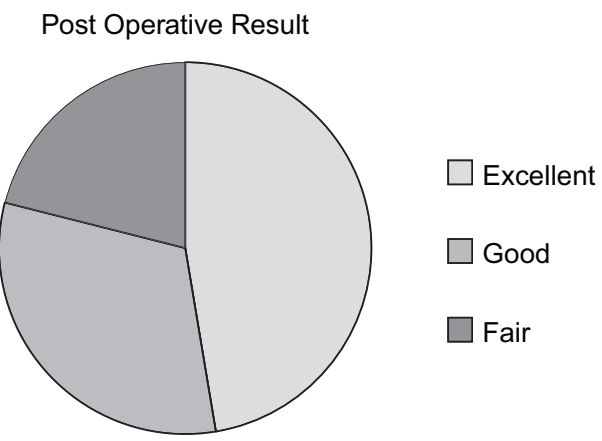

Fig.-2: Pie diagram showing post operative outcome after 3 months
In our series 1 patient (5.26\%) developed serous discharge which recovered with antibiotic treatment after culture and sensitivity.

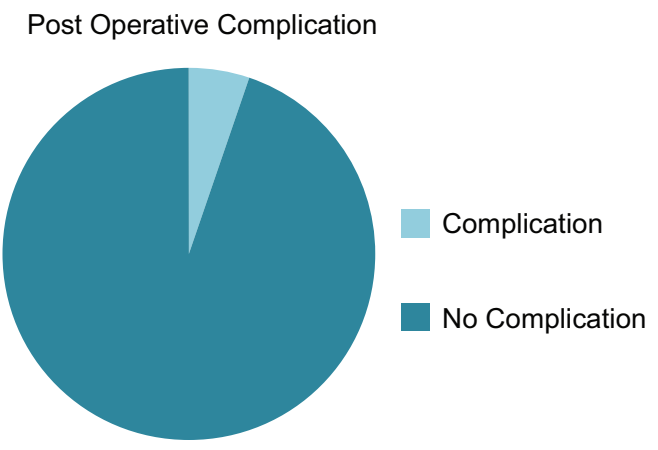

Fig.-3: Pie diagram showing post operative Complication

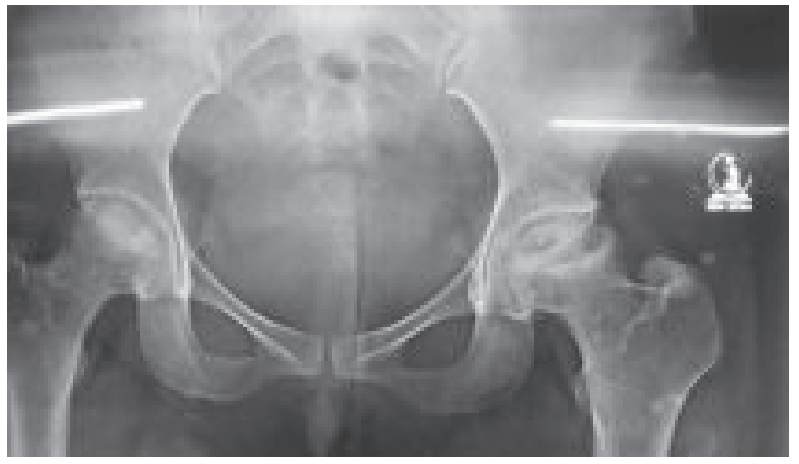

Fig.-4: Pre operative $x$-ray

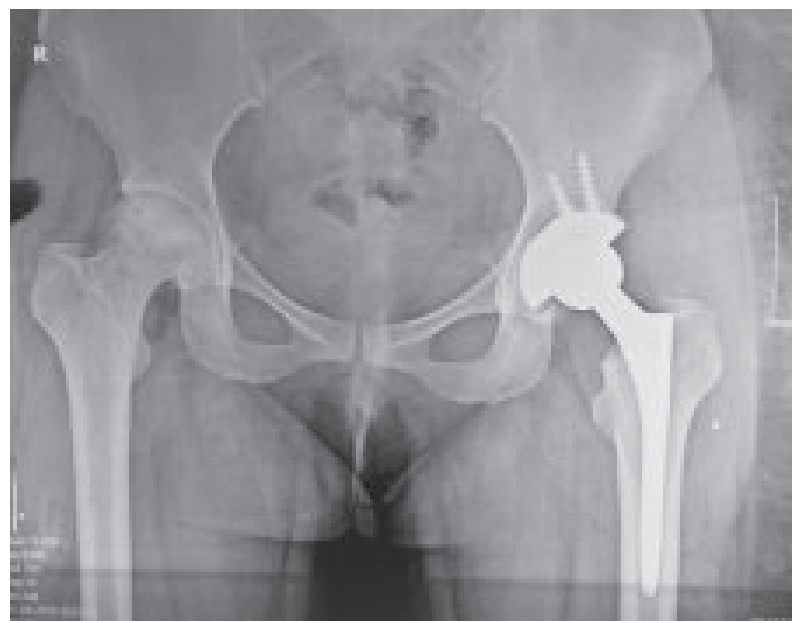

Fig.-5: Post operative $x$-ray after THR

\section{Discussion}

This study was done in the Department of Orthopedic Surgery, ShSMCH, Dhaka from July 2018 to June 2020. AVN of the hip affects people of all ages, although it is most commonly seen in patients between the ages of 30 and 65 years. ${ }^{3}$ In atraumatic AVN, the pathophysiology is poorly understood. ${ }^{4}$ Symptoms often improve 
spontaneously with time but joint replacement may be required in patients who have persisting pain in association with significant structural damage. ${ }^{4}$ Once there is structural damage and distortion of the articular surface, conservative operations are inappropriate. ${ }^{5}$ Improved results have been reported with modern cementing techniques and press fit cementless total hip arthoplasty. ${ }^{6}$ Receipients of crosslinked polyethylene cup liners experienced reduced femoral head penetration and revision. ${ }^{7}$ To eliminate pain and to improve quality of life we performed THR of these patients of Ficat and Arlet stage III and IV of AVN. In 2015 Sujit Kumar Tripathy et, al, showed in a study that $98 \%$ stem survivorship in both cemmented and cementless and $85 \%$ cementless cup survivorship found after 17.3 years. ${ }^{8}$ Choosing the appropriate patient for surgery is crucial for good outcome in THR. In our study we found significant improvement of pain and function. $47.36 \%$ found excellent, $31.57 \%$ good of $21.05 \%$ fair outcome according to Harris Hip Score, 3 months post-operatively after THR. This result also supports other study as shown by Swarn Gupta et, al, in Indian Journal of Orthopedics. In his study he found excellent result in $36 \%$ cases and good result in $42 \%$ cases $^{9}$.

\section{Conclusions}

Total Hip Replacement significantly improved Ficat and Arlet stage III and IV of AVN of femoral head in all patients of our series. Out of 19 patients, 15 patients obtained good to excellent result and 4 patients obtained fair result. None obtained poor result. Therefore THR should be considered as the most satisfying treatment option for end stage AVN of femoral head.

\section{References}

1. Jonathan T Evans, Jonathan P Evans, Robert W Walker, Prof. Ashley W Blom, Michael R Whitehouse, Adrian Sayers. How long does a hip replacement last? A systematic review and meta analysis of case series and national registry reports with more than 15 years follow-up. The Lancet. V-393, Issue 10172, P. 647-654, February 16, 2019.

2. Vikas Khanduja. Total Hip arthroplasty in 2017 Current Concepts and Recent Advances. Indian J. Orthop. V-51(4): P. 357-358 Jul-Aug 2017.

3. Michelle J Lespascio, Nipun Sodhi, Michael A Mont. Osteonecrosis of the Hip: A primer. The permenante Journal, 23, 18-100, 2019.

4. Stuart H. Ralston, Ian D Penman, Mark. W. J Strachan, Rchand P. Hobson. Davidson's Principles and Practice of Medicine $23^{\text {rd }}$ ed. P. 1055.

5. Ashley Blom, David Warwick, Michael R. Whitehouse. Apley and Solomon's system of orthopacdics and trauma. $10^{\text {th }}$ ed. P. 113.

6. S. Terry Canale, Kay Daugherty, Linda Jones. Campbell's Operative Orthopaedics. $10^{\text {th }}$ ed. P.955.

7. Alexander Tsertsvadze, Amy Grove, Karoline Freeman, Rachel Count, Samantha Johnson, Martin Connock, Allen Clarke, Paul Sutcliffe. Total Hip Replacement for the treatment of end stage arthritis of the Hip. A systematic review and Meta Analysis. Journal pone 0099804, July 8, 2014.

8. Sujit Kumar Tripathy, Tarun Goyal, Ramesh Kumar Sen. Management of femoral head Osteonecrosis; Current Concepts. Indian J. Orthop Jan-Feb, 49 (1) : 28-45, 2015.

9. Gupta S., Singh P.K., Despande S., Khan S., To study the clinical outcome of total hip arthoplasty. Indian Jaurnal of Orthopaedic Surgury 2017; 3(4): 350-355. 